\title{
TRABALHO INFANTIL COMO EMPECILHO AO DESENVOLVIMENTO DAS CRIANÇAS E ADOLESCENTES E A PROMOÇÃO DO TRABALHO DECENTE
}

\author{
Analice Schaefer de Moural \\ Marli M. Moraes da Costa ${ }^{2}$
}

\begin{abstract}
RESUMO
O presente estudo analisar as formas em que o trabalho infantil se insurge como um grande obstáculo ao trabalho decente e ao desenvolvimento humano, tendo em consideração não só seus efeitos imediatos, mas também seus reflexos futuros na vida das crianças e adolescentes explorados. Ainda, apresenta o trabalho infantil enquanto fenômeno multifatorial, analisando suas principais consequências no desenvolvimento dos infantes. As análises realizadas apontam que várias são as causas, formas e consequências do trabalho infantil. Conclui-se que, para combater a exclusão e garantir a cidadania, de fato e de direito, o Estado deve implantar instrumentos capazes de viabilizar tais direitos. Trata-se de políticas públicas intersetoriais, que, no caso dos direitos das crianças e dos adolescentes, devem contar com a participação do Estado, da sociedade, da família e da iniciativa privada. A técnica de pesquisa utilizada foi a bibliográfica (artigos e livros) e o método utilizado foi o hipotético-dedutivo, partindo-se da análise dos fatores que levam ao trabalho infantil e suas principais consequências para, após, buscar o referencial mais específico no que tange políticas públicas intersetoriais e sua aplicação nas diversas consequências e fatores do trabalho infantil.
\end{abstract}

Palavras-chave: Direito contra exploração. Políticas públicas intersetoriais. Trabalho infantil.

\begin{abstract}
This study aims to examine the ways that child labor protests as a major obstacle to decent work and human development, taking into account not only its immediate effects, but also its future effects on the lives of children and adolescents exploited. Furthermore, aims to understand child labor while multifactorial, analyzing its main consequences on the development of children and adolescents. This analysis notices that there are several causes, and consequences of child labor. It is concluded that to combat exclusion and ensure the citizenship of fact and law, the state must deploy instruments to facilitate such rights. Those are intersectoral public policies, in which case the rights of children and teenagers should have the participation of the state, society, family and private initiative. The technique used during the research was the bibliographic (articles and books) and the method used was the hypothetical-deductive, starting from the analysis of the factors leading to child labor and its main consequences in order to, after, look over the specific references regarding intersectoral public policies and their implementation in the various factors and consequences of child labor.
\end{abstract}

Keywords: Right against exploitation. Intersectoral public policies. Child labor.

\footnotetext{
${ }^{1}$ Graduanda em Direito pela Universidade de Santa Cruz do Sul - UNISC. <analice_sm@ hotmail.com>

2 Professora da Graduação e do Programa de Pós Graduação em Direito (Mestrado e Doutorado) da Universidade de Santa Cruz do Sul - UNISC. <marlicosta15@yahoo.com.br>
} 


\section{INTRODUÇÃO}

A expressão trabalho infantil não é definida igualmente por todos os autores, existindo diversas compreensões, abordagens e temáticas utilizadas. Ocorre que o trabalho infantil é um tema complexo, com causas profundas e, ainda, motivo de polêmicas e contradições. Trata-se de um problema político, cultural e social.

Apesar de se tratar de um problema multifatorial, existem questões comuns a todos os lugares onde ocorre. Dentre elas, destacam-se a pobreza, a ineficiência do sistema educacional brasileiro e a própria tradição cultural da sociedade, que enxerga no trabalho precoce diversos benefícios distorcidos sobre educação para o trabalho, geração de renda e ocupação para essas crianças adultas. Em se tratando da pobreza, cabe ressaltar que ela é, ao mesmo tempo, causa e consequência do trabalho infantil, devendo as políticas de prevenção e enfrentamento levar este fato em conta no momento de programar suas ações.

A importância do estudo sobre esse tema está vinculada às profundas influências negativas no desenvolvimento humano dos infantes, bem como à discussão sobre a aplicação e eficiência das políticas públicas voltadas para essa faixa etária. Nesse viés, o presente estudo pretende fazer uma reflexão sobre a persistência do trabalho infantil e sua repercussão no sistema jurídico brasileiro. No decorrer da pesquisa, foi utilizado como método de abordagem o hipotético-dedutivo. Para tanto, partiu-se da análise dos fatores que levam ao trabalho infantil e suas principais consequências para, após, buscar o referencial mais específico no que tange quais políticas públicas seriam efetivas e da necessidade de se fazer um diagnóstico, implementação e monitoramento destas.

Para tanto, utilizou-se como técnica a pesquisa bibliográfica como base teórica do estudo. Foi realizado levantamento bibliográfico, bem como levantamento documental, principalmente de relatórios do Ministério da Saúde e da Organização Internacional do Trabalho - OIT. As fontes utilizadas permitiram uma melhor fundamentação no trabalho desenvolvido, além de proporcionarem a diversificação da abordagem para concretizar os objetivos propostos. 


\section{A PERSISTENNCIA DO TRABALHO INFANTIL FRENTE À PECULIAR SITUAÇÃO DE DESENVOLVIMENTO DE CRIANÇAS E ADOLESCENTES}

O reconhecimento da criança e do adolescente enquanto sujeitos de direitos, sendo considerados conforme suas capacidades e seu grau de desenvolvimento, vem a ser uma conquista recente da sociedade brasileira. Tal mudança se deu principalmente pela promulgação Constituição Federal de 1988 e do Estatuto da Criança e do Adolescente - ECA em 1990, bem como com a ratificação da Convenção dos Direitos da Criança, em 1990, com a Lei Orgânica da Assistência Social - LOAS, em 1993 (PRESIDÊNCIA DA REPÚBLICA, 2006). Outrossim, tem-se expressamente no artigo 227 da Constituição Federal de $1988^{3}$ que compete à família, juntamente com o Estado e a sociedade em geral, assegurar os direitos fundamentais da criança e do adolescente. A Constituição brasileira consolidou nesses direitos o status de prioridade absoluta.

Em relação aos direitos de proteção, previstos no artigo referido, foi contemplada a proteção contra a exploração. No mesmo sentido, o art. $7^{\circ}$, XXXIII da Constituição Federal, dispõe da proibição de trabalho infantil, permitindo o trabalho a partir dos 16 anos e, na condição de aprendiz, a partir dos 14 anos. Esse dispositivo estabelece os limites de idade mínima para adentrar no mundo do trabalho, definindo, assim, o conceito legal de trabalho infantil no Brasil.

Entretanto, há que se destacar a dificuldade de conceituar trabalho infantil. Existem diversas formas desta prática, como na agricultura, carvoarias, nas ruas, no tráfico de drogas, trabalho escravo, enfim, cada uma com características próprias, dificultando a formulação de um conceito único. Nesse viés, Liberati e Dias (2006) conceituam trabalho infantil como sendo o trabalho realizado pelos infantes abaixo da idade legalmente permitida para entrar no mercado de trabalho, e que possam ser consideradas tarefas insalubres e perigosas, que afetam suas integridades físicas, morais e psicossociais.

Também, é oportuno destacar a diferenciação entre trabalho infantil e tarefas realizadas dentro de casa. Segundo Costa e Cassol (2008), a tarefa não afeta a condição peculiar de desenvolvimento da criança e do adolescente, não muda sua rotina, não afeta seus estudos, lazer e integridade física. Já a exploração do trabalho infantil se configura quando os infantes têm seus direitos violados, sendo privados do direito de frequentar a escola, de

\footnotetext{
3 Art. 227. É dever da família, da sociedade e do Estado assegurar à criança e ao adolescente, com absoluta prioridade, o direito à vida, à saúde, à alimentação, à educação, ao lazer, à profissionalização, à cultura, à dignidade, ao respeito, à liberdade e à convivência familiar e comunitária, além de colocá-los a salvo de toda forma de negligência, discriminação, exploração, violência, crueldade e opressão (BRASIL, 1988).
} 
estudar com propriedade e de brincar, porque estão obrigadas com o trabalho. Disciplinam ainda as autoras:

\begin{abstract}
Dessa maneira, se estará diante de uma agressão aos direitos fundamentais desse infante, que constitucionalmente está protegido pelo princípio da prioridade absoluta, corolário da doutrina à proteção integral, que na prática não se consegue efetivar (COSTA; CASSOL, 2008, p. 12).
\end{abstract}

Ao lado da difícil conceituação de trabalho infantil, surge a dificuldade de encontrar e enumerar fatores que levam à inserção da criança no mundo do trabalho. Para elucidar os fatores que desencadeiam o trabalho infantil, é necessária a análise de inúmeros aspectos por se tratar de um problema social complexo, interligado a outros problemas conjunturais que estão presos à família, aos infantes e à comunidade.

$\mathrm{Na}$ análise da complexidade dos fatores ligados à existência do trabalho infantil, Custódio e Veronese (2007) afirmam que não é desejo da criança ingressar no mundo do trabalho. Porém, o faz pela precariedade econômica, pela sua sobrevivência e de sua família.

Consoante Rizzini et al. (1996), no tocante ao assunto, pode-se afirmar que a inserção da criança e do adolescente está ligada a uma multiplicidade de fatores. Além do mais, o trabalho de crianças e adolescentes é um fenômeno mundial, porém, é comum a ligação de trabalho infantil e pobreza. Nesse sentido, Costa e Cassol afirmam:

\footnotetext{
Como principal causa do trabalho infantil destaca-se a pobreza. Entre as demais estão o alto índice de desemprego, a precariedade educacional no país, a baixa escolaridade dos pais. São, portanto, aspectos econômicos, culturais, políticos que, de uma forma ou outra, influenciam o modo de viver e pensar em sociedade (COSTA; CASSOL, 2008, p. 12).
}

Ademais, ao analisar o fator econômico, também é possível que o desejo de consumo do grupo familiar, ou da própria criança ou adolescente, concebido como algo necessário, influencie o ingresso do infante no mundo do trabalho. Por mais que esse fator não seja determinante, ele pode aparecer como um impulso dentro de uma problemática mais ampla. Nesse contexto, é oportuno destacar que Rizzini et al. (1996) fazem uma crítica à relação imediatista entre trabalho infantil e pobreza, afirmando que não se pode confundir trabalho infantil como sendo apenas uma consequência e não, também, causa da pobreza. Ou seja, no mesmo momento em que a pobreza parece ser um fator determinante para o trabalho infantil, este é um fator central no que tange a pobreza. 
É nessa relação que se visualiza o ciclo da pobreza perpetuado por paradigmas. O trabalho infantil acaba sendo uma desafortunada herança passada de pais para filhos, juntamente com a pobreza, numa lógica invertida sobre o valor do trabalho na fase prematura.

\section{TRABALHO INFANTIL COMO EMPECILHO AO DESENVOLVIMENTO HUMANO DAS CRIANÇAS E ADOLESCENTES E A PROMOÇÃO DO TRABALHO DECENTE}

A persistência do trabalho infantil em nosso país reflete prejuízos à saúde das crianças e adolescentes, que estão muito mais expostos a riscos que o ambiente laboral pode trazer em relação a um adulto. Isto se dá justamente em razão de estarem passando por um processo de desenvolvimento.

A Conferência Internacional do Trabalho - CIT aprovou por unanimidade a Convenção sobre a Proibição das Piores Formas de Trabalho Infantil e a Ação Imediata para a sua Eliminação, Convenção 182, em 17 de junho de 1999. Até março de 2012, 95\% dos Estados-Membros da OIT à época tinha ratificado a Convenção, sendo aderida pelo Brasil em 02 de fevereiro de 2000 (GUIMARÃES, 2012).

A Convenção n..$^{\circ} 182$ abarca as pessoas menores de 18 anos de idade e define que as piores formas de trabalho infantil são as relacionadas com:

\footnotetext{
escravidão e práticas análogas, incluindo o trabalho forçado e o recrutamento para fins de conflitos armados; a utilização, recrutamento ou oferta de crianças para a realização de atividades ilícitas, exploração sexual ou atividades para fins pornográficos e formas de trabalho que, por sua natureza ou condição em que se realizem, sejam susceptíveis de prejudicar a saúde, segurança e a moralidade das crianças (GUIMARÃES, 2012, p. 160).
}

Sob esse prisma, percebe-se que o trabalho infantil também é um grande obstáculo ao trabalho decente e ao desenvolvimento humano, levando em consideração não só seus efeitos imediatos, mas também seus reflexos futuros na vida das crianças e adolescentes exploradas. Uma pesquisa realizada pelo Programa Internacional Para Eliminação do Trabalho Infantil IPEC da OIT em 2005, analisando os dados da Pesquisa Nacional por Amostragem de Domicílios - PNAD, concluiu que a exploração do trabalho infantil resulta em menor renda na idade adulta, quanto mais prematura for a inserção no mercado de trabalho. A pesquisa indica que: 
(...) pessoas que começaram a trabalhar antes dos 14 anos de idade têm uma probabilidade muito baixa de obter rendimentos superiores aos $\mathrm{R} \$ 1.000$ mensais ao longo da vida. A maioria daquelas que entraram no mercado antes dos nove anos tem baixa probabilidade de receber rendimentos superiores a $\mathrm{R} \$ 500$ mensais. Em média, quem começou a trabalhar entre 15 e 17 anos não chega aos 30 anos com uma renda muito diferente de quem ingressou com 18 ou 19 anos (GUIMARÃES, 2012, p. 170).

Ainda sob esse respeito, Guimarães (2012) contextualiza que, na medida em que a pessoa envelhece, existe maior possibilidade de que consiga melhor renda do que quem começou a trabalhar entre 15 e 17 anos, caso tenha começado a trabalhar entre 18 a 19 anos. Preceitua o autor que a probabilidade de obter um rendimento superior ao longo da carreira laboral é maior para quem começa a trabalhar depois dos 20 anos. Um dos fatores que pode explicar essa relação é a possibilidade de que essas pessoas que começaram a trabalhar mais tarde tenham níveis superiores de escolaridade, qualificação ou profissionalização. Assim, o trabalho infantil se apresenta como um obstáculo ao trabalho decente no momento em que prejudica a criança ou adolescente no desenvolvimento de suas capacidades, as quais posteriormente seriam utilizadas no mundo laboral. Nesse prisma, Rizzini et al. (1996) afirma:

\begin{abstract}
a infância que se extenua no trabalho está sendo impedida de se educar e de se dedicar a atividades próprias à sua faixa etária. Isso significa que cada uma destas crianças está sendo prejudicada o desenvolvimento de suas capacidades à sua faixa etária. Isso significa que cada uma destas crianças está sendo prejudicada no desenvolvimento de suas potencialidades. A dimensão social de problema está em que parte da população mundial permanece, dessa forma, privada do direito básico à cidadania: são indivíduos precocemente entregues à própria sorte na luta pela sobrevivência; são destinados à desqualificação, discriminados e usados em regime que se assemelha à escravatura (p. 19-20).
\end{abstract}

Importante salientar que as capacidades laborais dos infantes ainda estão em formação e as condições em que as atividades laborais são exercidas se dão geralmente em ambientes insalubres e inadequados "do ponto de vista ergonômico, proporcionando não só acidentes, mas também doenças osteomusculares, já que os instrumentos não são dimensionados para elas" (GUIMARÃES, 2012, p. 174). Ainda, conforme o autor supramencionado, em 2010 foi registrada uma média de aproximadamente 3,03 acidentes graves por dia envolvendo crianças e adolescentes no mercado laboral. Já nos oito primeiros meses de 2011 registrou-se 2,58 acidentes graves por dia para este mesmo grupo de população ocupada (GUIMARÃES, 2012).

Nesse contexto, de acordo com a Classificação Nacional das Atividades Econômicas - CNAE, as atividades que mais registraram acidentes graves envolvendo a exploração do 
trabalho infantil foram, respectivamente:

fabricação de calçados de qualquer espécie, cantinas (serviços de alimentação privativos), comércio varejista, comércio atacadista de hortifrutigranjeiros, lanchonetes e similares, comércio a varejo e por atacado de peças e acessórios de veículos, comércio varejista de atacadista em geral, com predominância de produtos alimentícios, comércio de balas, bombons e similares, comércio atacadista de tecidos, fios e armarinhos, comercio de bebidas, fabricação de vidro, fabricação de filmes cinematográficos, usinas de açúcar, atividades de organizações sindicais, comércio atacadista de produtos químicos, obras viárias, trabalho doméstico, transporte aquaviário, transporte rodoviário e agricultura, entre outros (GUIMARÃES, 2012, p. 176).

O processo físico, cognitivo, emocional e a natureza ou condição em que a atividade é realizada acabam por impedir o efetivo exercício da cidadania. A prevenção e erradicação do trabalho infantil se caracterizam como princípios e direitos fundamentais do trabalho e, dessa maneira, podem ser acentuadas como aspecto central na promoção do trabalho decente.

\section{POLÍticas PÚBLICAS INTERSETORIAIS COMO MECANISMO NAS TRATATIVAS E PREVENÇÃO DO TRABALHO INFANTIL}

É evidente que o trabalho infantil exige a formatação de novos e diversos instrumentos e mecanismos de repressão que, conjuntamente, atuarão erradicando ou dando descontinuidade a este evento no Brasil. A questão da exploração do trabalho infantil tem causas e razões que extrapolam um rol taxativo e único, tratando-se de uma multiplicidade de fatores como evidenciado anteriormente. Contudo, notadamente se observa que as questões culturais exercem influência acentuada e é especificamente nesse aspecto que as políticas públicas intersetoriais podem (e devem) atuar.

Antes de adentrar no tema das políticas públicas internacionais, no tocante à erradicação do trabalho infantil, é fundamental esclarecer o que são políticas públicas. Consoante Schmidt, o termo políticas públicas é utilizado com diferentes conotações, indicando um campo de atividade, um "propósito político" ou "um programa de ação ou os resultados obtidos por um programa" (SHIMIDT, 2008, p. 2312).

Políticas públicas são o meio de ação do Estado. É através delas que se orientam as ações de governo e da sociedade:

Políticas públicas configuram decisões de caráter geral que apontam rumos e linhas estratégicas de atuação governamental, reduzindo os efeitos da descontinuidade 
administrativa e potencializando os recursos disponíveis ao tornarem públicos, expressas e acessíveis à população e aos formadores de opinião as intenções do governo no planejamento de programas, projetos e atividades (MINISTÉRIO DA SAÚDE, 2006, p. 9).

Ainda sobre o assunto, políticas públicas podem ser entendidas como ações do Estado que garantem os direitos sociais, pois é através das políticas públicas que bens são "distribuídos e redistribuídos" em resposta às demandas da sociedade. O Brasil possui um elevado número de crianças trabalhando. Por essa razão, é imprescindível a atenção dos governantes e da própria sociedade civil. Custódio e Veronese (2009) afirmam que no momento em que se decide que estas crianças devem deixar de trabalhar e se dedicar ao estudo e as brincadeiras, atividades típicas desta faixa etária, é importante que o Estado encontre mecanismos para evitar a falta de recursos financeiros necessários para subsistência da família, o que se visualiza com o Programa de Erradicação do Trabalho Infantil - PETI.

Nesse sentido, o PETI surgiu em 1996 com a finalidade de afastar do trabalho crianças e adolescentes até 16 anos de idade, permitindo, porém, às de 14 anos trabalhar na condição de aprendiz.

No ano de 2005 o PETI foi reformulado, passando a integrar o Sistema Único de Assistência Social - SUAS, tendo três eixos básicos: distribuição de renda às famílias de crianças ou adolescentes em situação de trabalho, atividades de convivência e fortalecimento de vínculos para estas crianças e adolescentes, e acompanhamento familiar por meio do Centro de Referência de Assistência Social - CRAS e Centro de Referência Especializado de Assistência Social - CREAS (COSTA; AQUINO, 2012).

Paralelamente a isso, é preciso reconhecer que com o Sistema Único de Saúde SUS, o Brasil inaugurou uma rede de políticas públicas de atendimento descentralizada de longo alcance, permitindo novas alternativas de prevenção e erradicação do trabalho infantil mais próximas das famílias (CUSTODIO et al., 2010).

Sob essa perspectiva, a efetivação do direito à saúde das crianças e adolescentes como instrumento de prevenção e erradicação do trabalho infantil contempla a necessidade de uma análise dos modelos de vigilância da saúde, remodelação da atenção básica e da promoção da saúde. Isto proporciona a integração do sistema de saúde na rede de articulação de políticas públicas intersetoriais para proteção de crianças e adolescentes contra a exploração do trabalho infantil no Brasil (NOBRE, 2003). Assim, a intersetorialidade e a integração da área da saúde e da educação com os direitos das crianças e dos adolescentes torna-se uma importante ferramenta para a promoção da prevenção e erradicação da 
exploração do trabalho infantil.

Enfim, para combater a exclusão e garantir a cidadania, de fato e de direito, o Estado deve implantar instrumentos capazes de viabilizar tais direitos. Trata-se de políticas públicas intersetoriais que, no caso dos direitos das crianças e dos adolescentes, devem contar com a participação do Estado, da sociedade, da família e da iniciativa privada.

\section{CONCLUSÃO}

Infelizmente, o trabalho infantil ainda persiste em nosso país, o que reflete prejuízos aos infantes pela sua peculiar condição de pessoa em desenvolvimento. Essa violação destoa dos direitos constitucionalmente instituídos, como liberdade, igualdade, saúde, educação, cultura, esporte, lazer, dignidade prioridade absoluta, dentre outros tantos direitos fundamentais reconhecidos.

Diversos problemas podem ser elencados quando da incidência do trabalho infantil, como baixa escolarização, ou escolarização insuficiente, pouca ou inexistente profissionalização, doenças, problemas osteomusculares e problemas psicológicos. Ainda, pode-se citar aqui os acidentes de trabalho, visto que os aparelhos/utensílios laborais são dimensionados para serem utilizados por adultos, não sendo adaptados à estrutura da criança e do adolescente em desenvolvimento.

A prevenção e a erradicação do trabalho infantil podem ser elencadas como princípios e direitos fundamentais do trabalho. Outrossim, a exploração da mão de obra infantil se revela como empecilho ao trabalho decente e ao desenvolvimento das crianças e adolescentes.

É perceptível que, ao longo da história, o arcabouço jurídico brasileiro construído em relação ao tema do trabalho infantil evoluiu gradativamente. Porém, as normas jurídicas não conseguem surtir efeito sozinhas, como se pretendia ao prescrevê-las. Nesse sentido é que se buscam, como instrumento efetivo no combate e erradicação do trabalho infantil, políticas públicas intersetoriais, as quais devem produzir efeitos nos mais diversos campos, como saúde, educação, serviço social e o direito.

Nesse sentido, o direito da criança e do adolescente possui um potencial que abarca uma visão multidisciplinar e democrática, uma vez que necessita da participação dos diversos atores sociais. Além do mais, o Estatuto da Criança e do Adolescente - ECA, aliado à Constituição Federal, atribui responsabilidade compartilhada do Estado, da família e da 
sociedade em relação à efetivação dos direitos dos infantes.

Assim, se vê potencial nas políticas públicas intersetoriais como instrumentos eficientes para combater a exclusão e garantir a cidadania, de fato e de direito, das crianças e adolescentes.

As estratégias de garantias de direitos da criança e do adolescente para erradicação do trabalho infantil no âmbito das políticas públicas socioassistenciais devem estar amparadas pela Constituição Federal, a qual reconhece o direito dos infantes ao não trabalho e situa a Assistência Social no rol da proteção integral dos infantes.

O enfrentamento do trabalho infantil deve constituir-se como política prioritária de Estado, pois, além das consequências nefastas às crianças e aos adolescentes, apresenta riscos à própria democracia, tendo em vista que a inserção precoce no trabalho dificulta o acesso à informação necessária para o exercício pleno dos direitos de cidadania.

\section{REFERÊNCIAS}

ACOSTA, A. R.; VITAle, M. A. F.; CARVAlHO, M. C. B. Famílias beneficiadas pelo programa de Renda Mínima em São José dos Campos/SP: aproximações avaliativas. In: ACOSTA, A. R.; VITALE, M. A. F.; (Org.). Família: redes, laços e políticas públicas. 4 ed. São Paulo: Instituto de Estudos Especiais da Pontifícia Católica de São Paulo, 2002.

BRASIL. Lei 8069, de 13 de julho de 1990. Institui o Estatuto da Criança e do Adolescente. Diário Oficial [da] República Federativa do Brasil, Brasília, DF, 16 jul. 1990. Disponível em: <http://www.planalto.gov.br/ccivil_03/leis/L8069.htm>. Acesso em: 10 de jul. de 2012.

BRASIL. Constituição da República Federativa do Brasil. Brasília, DF: Senado Federal, 1988.

CARVALHO, M. do C. B. de. Famílias e políticas públicas. In: ACOSTA, A. R.; VITALE, M. A. F. (Orgs.). Família: redes, laços e políticas públicas. 4 ed. São Paulo: Instituto de Estudos Especiais da Pontifícia Católica de São Paulo, 2002.

CIPOLA, A. O trabalho infantil. São Paulo: Publifolha, 2001.

CORREAA, C. P.; GOMES, R. S. Trabalho infantil: as diversas faces de uma realidade. Petrópolis: Viana e Mosley, 2003.

COSTA, M. M. M.; AQUINO, Q. B. O Direito de proteção contra a exploração do trabalho infantil por meio das Políticas Públicas: a necessária integração entre Estado, Sociedade e Família. In: IV SEMINÁRIO INTERNACIONAL DIREITOS HUMANOS, VIOLÊNCIA E POBREZA: A SITUAÇÃO DE CRIANÇAS E ADOLESCENTES NA AMÉRICA LATINA. Rio de Janeiro, 2012. Rio de Janeiro: Editora Rede Sirius - UERJ, v. 1, p. 30-40, 2012. 
COSTA, M. M. M.; CASSOL, S. Alternativas basilares para a tão almejada erradicação do trabalho infantil. In: COSTA, M. M. M. da; TERRA, R. B. M. da R. B.; RICHTER, D. (Org.). Direito, Cidadania e Políticas Públicas III. 1 ed. Porto Alegre: UFRGS, 2008.

CUSTÓDIO, A. V.; COSTA, M. M. M.; REIS, S. da S. O direito de proteção contra a exploração do trabalho infantil e as políticas públicas de saúde no Brasil. In: COSTA, M. M. M. da; PORTO, R. T. C.; REIS, S. da S. (Org.). Direito, Cidadania e Políticas Públicas IV. Curitiba: Multidéia Editora, 2010.

CUSTÓDIO, A. V.; VERONESE, J. R. P. Crianças esquecidas: o trabalho infantil doméstico no Brasil. Curitiba: Multidéia, 2009.

Trabalho Infantil: a negação de ser criança e adolescente no Brasil. Florianópolis: $\mathrm{OAB} / \mathrm{SC}, 2007$.

GUIMARÃES, J. R. S. Perfil do Trabalho Decente no Brasil: um olhar sobre as Unidades da Federação. Brasília: OIT, 2012.

LIBERATI, W. D.; DIAS, F. M. D. Trabalho Infantil. São Paulo: Malheiros, 2006.

MARQUES, J. B. A absoluta prioridade da criança e do adolescente sob a ótica do princípio da dignidade da pessoa humana. Jus Navigandi, v. 16, n. 2837, 2011. Disponível em: <http://jus.com.br/revista/texto/18861>. Acesso em: 6 de mar. de 2012.

MINISTÉRIO DA SAÚDE. Política nacional de plantas medicinais e fitoterápicos. Brasília, 2006.

NOBRE, L. C. C. Trabalho de crianças e adolescentes: os desafios da intersetorialidade e o papel do Sistema Único de Saúde. São Paulo: Revista Ciência \& Saúde Coletiva, v. 8, n. 4, p. $963971,2003$.

PRESIDÊNCIA DA REPÚBLICA. Plano Nacional de Promoção, Proteção e Defesa do Direito de Crianças e Adolescentes à Convivência Familiar e Comunitária. Brasília/DF, 2006. Disponível em: <http://www.tjpe.jus.br/coordvinf/arquivos/plano_nacional.pdf> Acesso em: 09 de mar. de 12.

In: PEREIRA, T. da S. O melhor interesse da criança: um debate interdisciplinar. Rio de Janeiro: Renovar, 1999.

RIZZINI, I.; RIZZINI, I.; HOLANDA, F. R. B. de. A criança e o adolescente no mundo do trabalho. Rio de Janeiro: USU, 1996.

SAETA, B. R. P.; SOUZA NETO, J. C. de. A criança e o adolescente na sociedade brasileira. In: SOUZA NETO, I. C. de; NASCIMENTO, M. L. B. P. (Org.). Infância: violência, instituições e políticas públicas. São Paulo: Expressão e Arte, 2006.

SCHMIDT, J. P. Para entender as políticas públicas: aspectos conceituais e metodológicos. In.: REIS, Jorge R.; LEAL, R. G. Direitos Sociais e Políticas Públicas: desafios contemporâneos. Tomo 8. Santa Cruz do Sul: Edunisc, 2008-. 
TEIXEIRA C. F.; PAIM J. S. Planejamento e programação de ações intersetoriais para a promoção da saúde e da qualidade de vida. In.: TEIXEIRA, C. F.; PAIM J. S. e VILASBÔAS, A. S. L. (Org.). Promoção e vigilância da saúde. Salvador: Cooptec/ISC, 2002.

VERONESE, J. R. P.; COSTA, M. M. M. da. Violência doméstica: quando a vítima é a criança ou adolescente - uma leitura interdisciplinar. Florianópolis: OAB/S C Editora, 2006. 